\title{
Stored elastic energy in aluminium alloy AA 6063 billets: residual stress measurements and thermomechanical modelling
}

\author{
J.-M. Drezet*1, A. Evans ${ }^{2}$, T. Pirling ${ }^{3}$ and B. Pitié ${ }^{4}$
}

Stress relief treatment before machining and sawing aluminium direct chill cast products is required to avoid uncontrolled distortion, crack formation and significant safety concerns due to the presence of thermally induced residual stresses created during casting. Numerical models have been developed to compute these residual stresses and yet have only been validated against measured surface distortions. In the present contribution, the variations in residual strains and stresses have been measured using neutron diffraction and hole drilling strain gage in two AA 6063 grain refined cylindrical billet sections cast at two casting speeds. The measured residual stresses compare favourably with the numerical model, in particular the depth at which the axial and hoop stresses change sign. Such results provide insight into the development of residual stresses within castings and show that the stored elastic energy varies linearly with the casting speed, at least within the range of speeds that correspond to production conditions.

Keywords: Aluminium billet casting, Residual stresses, FE modelling, Neutron diffraction, Hole drilling strain gage, Elastic energy

\section{Introduction}

In the fabrication of aluminium extrusion products, the first step is the semicontinuous casting of a cylindrical billet. The most commonly used process is known as direct chill (DC) casting. ${ }^{1}$ This process gives rise to large thermally induced strains that lead to several types of casting defects (distortions, cracks, porosity, residual stresses, etc.). During casting, thermally induced stresses are partially relieved by permanent deformation. When these residual stresses overcome the deformation limit of the alloy, cracks are generated during either solidification (hot tears) or cooling (cold cracks). The formation of these cracks usually results in rejection of the cast part. Furthermore, the thermally induced deformations can cause downstream processing issues during the sawing stage before extrusion, when the billet is cut without thermal annealing between casting and sawing. For large diameter and high strength alloys, sawing becomes a delicate task owing to the risk of saw pinching or crack initiation ahead of the saw. Parts might be ejected and injure people or damage the equipment.

\footnotetext{
${ }^{1}$ LSMX, Ecole Polytechnique Fédérale de Lausanne, Station 12, Lausanne $\mathrm{CH}-1015$, Switzerland

${ }^{2}$ Paul Scherrer Institut, PSI, Villigen $\mathrm{CH}-5232$, Switzerland

${ }^{3}$ Institut Laue Langevin, ILL, Grenoble F-38042, France

${ }^{4}$ Constellium CRV, Voreppe F-38341, France

*Corresponding author, email jean-marie.drezet@epfl.ch
}

The computation of stresses during DC casting of aluminium alloys has been the scope of several studies since the late $1990 \mathrm{~s}^{2-10}$ and is a well established technique nowadays. Many numerical models have allowed researchers to compute the ingot distortions and the associated residual stresses. The validation of these models was often carried out by comparing the computed and measured ingot distortions, e.g. the butt $\operatorname{curl}^{8}$ and the rolling face pull-in for rolling sheet ingots produced by $\mathrm{DC}^{9}$ or electromagnetic casting. ${ }^{11}$

Validation against the computed room temperature residual stresses is limited simply owing to the difficulty of measuring the internal strains and the high variability in the measurements. While some measurements are available for quenching ${ }^{12}$ or welding, ${ }^{13}$ they remain rare, uncertain and usually are limited to one or two components of the stress tensor and to the skin of the billet for as cast materials. ${ }^{14,15}$ In contrast to destructive methods for measuring residual stresses (hole drilling strain gage, cut compliance and layer removal technique), physical methods such as neutron, X-ray or ultrasound diffraction are very attractive ${ }^{16}$ since they can yield all the stress components. In addition, the use of physical methods allows for measurements deep within a sample up to the energy limit of the beam. With the development of powerful neutron beams, it is now possible to measure the residual strains rather deep in light metal alloys, such as aluminium and magnesium, since these metals are relatively transparent to neutrons, ${ }^{17,18}$ as opposed to copper and iron. Such measurements allow for sophisticated model validation. 
The finite element (FE) model used to compute the stress build-up during casting is fully detailed in Ref. 18 together with the thermal and mechanical properties used for AA 6063 alloy. Using this model, the sawing itself was modelled by the removal of elements, similar to the strategy adopted by Drezet et al. ${ }^{19}$ to study the possible crack initiation and propagation. Before this, the axisymmetric results from the casting simulation above were exported onto a three-dimensional domain since the sawing process itself is not axisymmetric. Nevertheless, only half of the billet had to be modelled owing to the presence of a centreline symmetry plane. Finite elements were removed sequentially, thus simulating the advance of the saw within the billet. Any heating induced by sawing was ignored. This simplified but realistic computation showed that stress relaxation takes place over a distance of 1.5 times the billet radius on both sides of the groove. The result is that, for residual stress measurements, the minimum billet section length must be greater than at least three times the billet radius to ensure that the residual stresses at its midheight are not relaxed during sawing. In the current context, this corresponds to a section length of $48 \mathrm{~cm}$.

Residual strain measurements have been undertaken on two AA 6063 round billet sections $160 \mathrm{~mm}$ in radius $R, 0.6$ and $1 \mathrm{~m}$ in length and cast at 54 and $66 \mathrm{~mm} \mathrm{~min}{ }^{-1}$. The residual stress measurements have been carried out on two neutron diffractometers, POLDI at PSI-Villigen, Switzerland, ${ }^{20}$ and SALSA at ILL-Grenoble, France ${ }^{21}$ and at Alcan-CRV, Voreppe, France, using the hole drilling method on the billet surface. The goals of the present work are the following:

(i) validate the residual stresses predicted by the FE model of the DC casting process similar to the model previously developed by Drezet and Rappaz $^{2}$

(ii) compare the residual stress measurements carried out with two different neutron diffractometers and with the hole drilling method

(iii) assess the influence of the casting speed on the elastic energy stored in the as cast billet.

The section on 'Material and residual stress measurement techniques' provides a description of the material and the principles of residual stress measurement using neutron diffraction and the hole drilling method. The measurements are presented in the section on 'Results and discussion' for both casting speeds and compared with the values predicted by the FE model.

\section{Material and residual stress measurement techniques}

\section{Material}

The AA 6063 alloy is a heat treatable alloy. Its composition is shown in Table 1 . The solidus, coherence (corresponding to a solid fraction of $65 \%$ for a grain refined structure) and liquidus temperatures are reported in Table 1. These quantities were calculated using the software ProPHASE, based on a model proposed by Sigli et $a l^{22}$ The typical grain size in this casting was $100 \pm 30 \mu \mathrm{m}$ with a globulitic microstructure. No texture was found owing to the use of grain refiner.

A $5.5 \mathrm{~m}$ long extrusion billet, $320 \mathrm{~mm}$ in diameter, was cast semicontinuously at Alcan Aluminium Valais, Switzerland. After the transient start-up phase, the casting speed was set to a minimum stable speed of $54 \mathrm{~mm} \mathrm{m^{-1 }}$ for a cast length of $1 \mathrm{~m}$. Then, the casting speed was increased to the maximum allowable speed over the next $1.5 \mathrm{~m}$, keeping all the other casting parameters, such as cooling conditions, constant. The rest of the billet was cast at $66 \mathrm{~mm} \mathrm{~min}^{-1}$. The two billet sections, $60 \mathrm{~cm}$ and $1 \mathrm{~m}$ in length, were sawed from the two steady state casting regimes at 54 and $66 \mathrm{~mm} \mathrm{~min}^{-1}$ and transported to PSI-Villigen and ILL-Grenoble for neutron diffraction residual stress measurements. The weights of the two billet samples were $130 \mathrm{~kg}$ for the $60 \mathrm{~cm}$ long section $\left(66 \mathrm{~mm} \mathrm{~min}^{-1}\right)$ and $217 \mathrm{~kg}$ for the $1 \mathrm{~m}$ long section $\left(54 \mathrm{~mm} \mathrm{~min}^{-1}\right)$. M16 holes were drilled at both extremities for manipulation.

\section{Neutron diffraction at POLDI and SALSA}

POLDI $^{20}$ and SALSA ${ }^{21}$ are neutron diffraction instruments designed for strain measurements through the accurate determination of lattice spacing. In a stressed material, the lattice spacing acts as a kind of strain gauge. The elastic strain is given by $\varepsilon=\left(d-d_{0}\right) / d_{0}$, where $d_{0}$ and $d$ are the stress free and actual lattice spacings respectively for a given crystal plane family. Using Hooke's law, the measured strain can be converted to stress with the appropriate elastic constants. Diffraction can be understood in terms of Bragg's law $\lambda=2 d \sin \theta$, where $d$ is the lattice spacing, $\lambda$ is the wavelength and $2 \theta$ is the diffraction angle. Therefore, in order to measure the lattice spacing for determining strains and stresses, either the wavelength is fixed and the diffraction angle is measured (monochromatic angular dispersive) or the diffraction angle is fixed and the wavelength determined (polychromatic time of flight). In the case of monochromatic, where only one diffraction peak is recorded, for fcc metals such as aluminium, the (311) diffracting planes are commonly used to measure the strain since they do not accumulate significant intergranular stresses and hence exhibit similar behaviour as that of the bulk. The (311) is also recommended for use in the measurement of residual strains by neutrons in aluminium alloys by the ISO VAMAS standard. ${ }^{23}$ This is the case of the measurements made on SALSA. In contrast with the time of flight method, many diffraction peaks are measured corresponding to several families of lattice planes. Using a full pattern refinement, an average lattice parameter is determined from which strain and stress are subsequently calculated. With this method, the range of elastic and plastic anisotropies is averaged, giving strain response akin to that of the bulk. This is the case with POLDI measurements.

Table 1 Composition and solidification temperatures of AA 6063 alloy computed using software ProPHASE ${ }^{22}$

\begin{tabular}{|c|c|c|c|c|c|c|c|c|c|c|}
\hline \multirow[b]{2}{*}{ AA 6063} & \multicolumn{7}{|c|}{ Content/wt- \% } & \multicolumn{3}{|c|}{ Temperature $/{ }^{\circ} \mathrm{C}$} \\
\hline & $\mathrm{Si}$ & $\mathrm{Fe}$ & $\mathrm{Cu}$ & $\mathrm{Mn}$ & $\mathrm{Mg}$ & $\mathrm{Cr}$ & $\mathrm{Zn}$ & Solidus & Coherence & Liquidus \\
\hline Min., max. & $0.20,0.60$ & -0.35 & $-0 \cdot 10$ & $-0 \cdot 10$ & $0.45,0.9$ & $-0 \cdot 10$ & $-0 \cdot 10$ & 557 & 610 & 655 \\
\hline
\end{tabular}




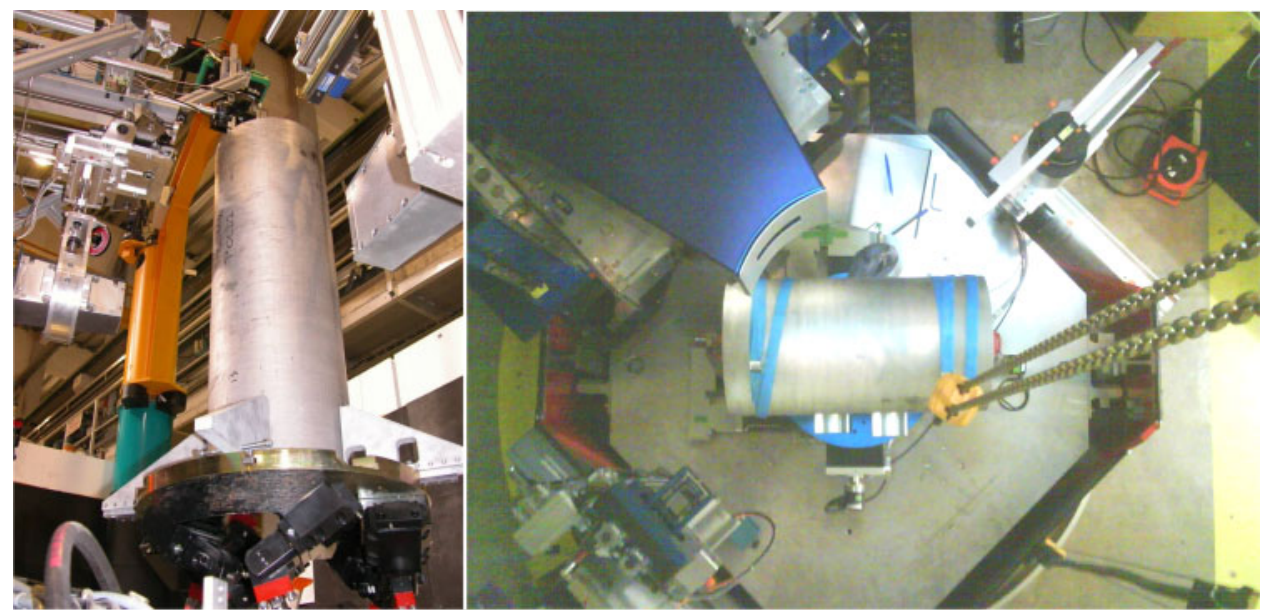

1 Billet section positioning for measuring radial strains at SALSA (left) and axial strains at POLDI (right)

POLDI is a so called time of flight instrument, which means that the detector is placed at a fixed diffraction angle $\left(90^{\circ}\right)$ and that, in contrast to monochromatic instruments, a broad wavelength spectrum is used. For the measurements at POLDI, a $3.8 \mathrm{~mm}$ collimator was used to define the sampling gauge volume. This rather large gauge volume $(3.8 \times 3.8 \times 8 \mathrm{~mm})$ gave reasonable measurement times, typically $2 \mathrm{~h}$ per position per strain component. A series of stress free reference samples, for the measurement of the reference lattice constant $d_{0}$, were also acquired. These samples were electrodischarge machined along the billet radius every $20 \mathrm{~mm}$ in order to account for any variation in $d_{0}$ with position within the billet that may be present due to long range chemical inhomogeneities, i.e. macrosegregation. Located at ILLGrenoble, SALSA uses a large crystal monochromator to select a particular neutron wavelength. The material to be studied is placed in this monochromatic neutron beam, and the scattered neutrons are collected on a large two-dimensional detector to determine accurately the lattice spacing. The wavelength is constant $(1 \cdot 66 \AA)$, and the position of the diffraction peak is recorded on a position sensitive detector. For the measurements at SALSA, $2 \mathrm{~mm}$ radial focusing collimators were used to reduce experimental errors introduced by the optics. A rather large instrumental gauge volume $(2 \times 2 \times 15 \mathrm{~mm})$, but with good lateral resolution in the scan direction, gave reasonable measurement times of on average $30 \mathrm{~min}$. Again, a series of stress free reference samples, for measurement of the reference lattice constant $d_{0}$, were acquired.

\section{Residual stress state in as cast extrusion billets}

In the DC casting of extrusion billets, the stress tensor has only four components due to the axisymmetric billet geometry and casting conditions. Furthermore, since the billet section used for the residual strain measurements was taken from a part corresponding to the steady state regime of casting, it can be assumed that this tensor depends only on the radial position. Finite element calculations $^{18,24}$ have also shown that the fourth component of stress $\sigma_{\mathrm{rz}}$ is negligible, thus further reducing the stress-strain tensor to three components, i.e. radial, hoop and axial. This tensor is therefore diagonal in the $(r, \theta, z)$ reference frame and can be described by Hooke's law $\sigma=\left(\begin{array}{c}\sigma_{r} \\ \sigma_{\theta} \\ \sigma_{z}\end{array}\right)=\frac{E}{(1+v)(1-2 v)}\left(\begin{array}{ccc}1-v & v & v \\ v & 1-v & v \\ v & v & 1-v\end{array}\right)\left(\begin{array}{c}\varepsilon_{r} \\ \varepsilon_{\theta} \\ \varepsilon_{z}\end{array}\right)$

where $E$ is Young's modulus $(71.3 \mathrm{GPa})$ and $v$ is Poisson's ratio $(0 \cdot 3)$.

For each of the three measured strain components, both the beam orientation and the position of the billet within the neutron chamber must be varied, as shown in Fig. 1. For the radial component, the length of the beam path varies from almost zero at the billet surface to $2 R$ at the billet centre. For the axial component, the beam path remains near $2(2)^{1 / 2} R$ for each measurement location, whereas for the hoop component, the beam path increases from $2^{1 / 2} R$ at the billet surface to $2 R$ at the billet centre. Obviously, the count times for the axial measurements are the longest. ${ }^{17}$

\section{Hole drilling method}

A classic technique for measuring residual stress is the hole drilling strain gage method of stress relaxation. ${ }^{25}$ Briefly summarised, the measurement procedure involves five basic steps:

(i) a special three-element strain gage rosette is installed on the test part at the point where residual stresses are to be determined as shown in Fig. 2

(ii) the gage grids are wired and connected to a multichannel static strain indicator; a precision milling guide is attached to the test part and

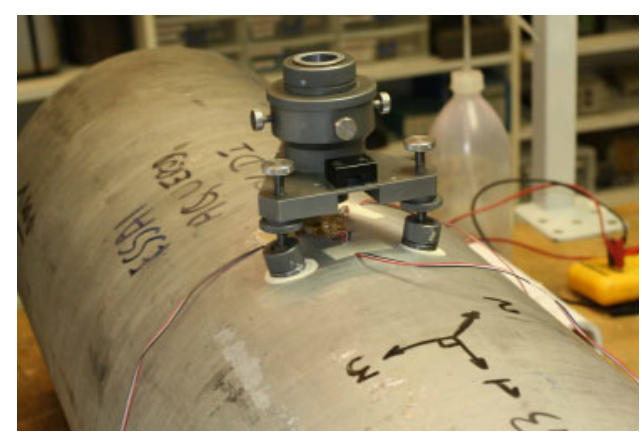

2 Measurement of surface residual stresses using hole drilling method 


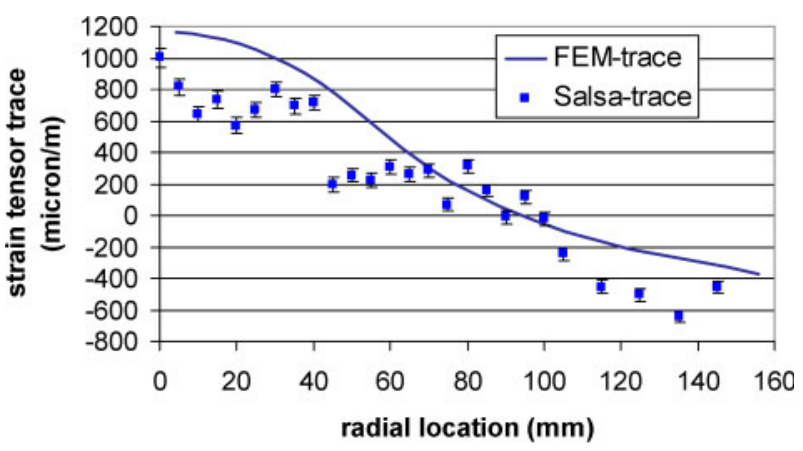

3 Comparisons between computed and measured traces of elastic strain tensor for billet section cast at $54 \mathrm{~mm} \mathrm{~min}{ }^{-1}$

accurately centred over a drilling target on the rosette

(iii) after zero balancing the gage circuits, a small, shallow hole is drilled through the geometric centre of the rosette

(iv) readings are made of the relaxed strains, corresponding to the initial residual stress

(v) using special data reduction relationships, the principal residual stresses and their angular orientation are calculated from the measured strains.

The procedure is relatively simple and has been standardised in ASTM standard test method E837. ${ }^{26}$ The major drawbacks of hole drilling are twofold: first, it can be applied only on the billet surface as it assumes that the stress component normal to the surface should remain close to zero, and second, hole drilling might induce plastic deformation, thus introducing some substantial errors in highly stressed parts.

\section{Results and discussion}

\section{Billet cast at $54 \mathrm{~mm} \mathrm{m^{-1 }}$}

Residual strains on the $1 \mathrm{~m}$ long AA 6063 billet section cast at $54 \mathrm{~mm} \mathrm{~min}{ }^{-1}$ were measured at the SALSA diffractomer. In total, roughly 16 residual strain measurements were made along the radius of the billet in $\sim 10 \mathrm{~mm}$ increments. The trace of the measured residual strains corresponding to the sum of the radial, hoop and axial elastic strains is presented in Fig. 3. To do so, the mean stress free lattice parameter, 4.0504 $\AA$ for the (311) diffracting planes, was used. The sum of the three as cast elastic strain components computed using the FE model of DC casting ${ }^{17}$ is also provided for comparison. The error bars are based on the scatter in

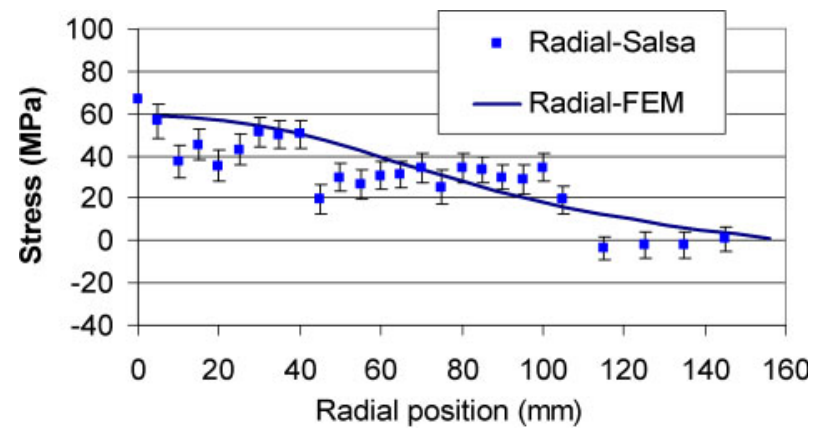

4 Comparison between computed and measured radial stress components within billet cast at $54 \mathrm{~mm} \mathrm{~min}^{-1}$

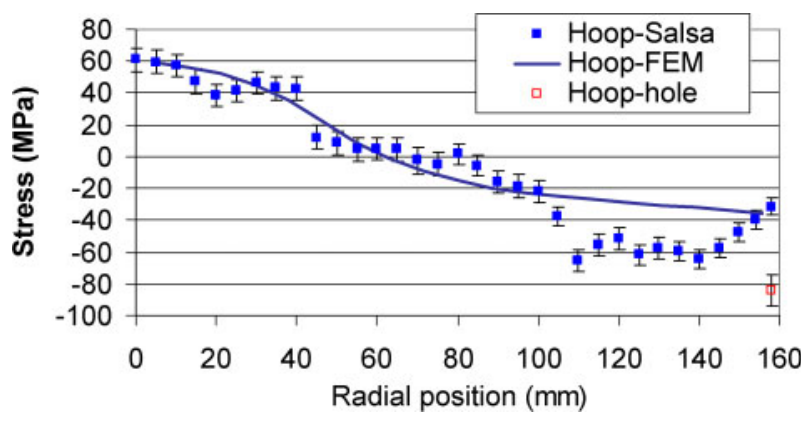

5 Comparison between computed and measured hoop stress components within billet cast at $54 \mathrm{~mm} \mathrm{~min} \mathrm{mi}^{-1}$

the measurements, which is a function of the beam path length within the billet. An important outcome of the measurements is that it was possible to measure all three strain components over the entire billet radius. Indeed, the neutron beam was intense enough to measure the axial strain at the centre of the billet for which the beam path length was longest, at $45 \mathrm{~cm}$.

When the trace of the elastic strain tensor is positive, the material is in tension, whereas when it is negative, it is in compression. This confirms our expectations; the centre of the billet is in triaxial tension, whereas its surface is in compression in the hoop and axial directions. Indeed, the trace of the elastic strain tensor is proportional to the trace of the stress tensor

$$
\sigma_{\mathrm{kk}}=\frac{E}{(1-2 v)} \varepsilon_{\mathrm{kk}}
$$

where an implicit summation of the repeated indices is assumed. In our case, the factor $E /(1-2 v)$ is equal to $177 \mathrm{GPa}$.

The radial distribution of the three stress components has been calculated at each radial position using equation (1). These stresses are shown in Figs. 4-6, along with the predicted stresses from the FE model and the hoop and axial values measured at the billet surface using the hole drilling method. The error on strain measurement is reported on each of the points using elastic constants. Again, the error becomes rather large for the axial stress. In a similar fashion to residual strains, the centre of the billet is in triaxial tension, whereas its surface is in compression in the hoop and axial directions, as already reported by Hannart et al. ${ }^{3}$ and Fjaer and Mo. ${ }^{4}$ This residual stress state develops because of the fast surface cooling rates applied during the casting process, which efficiently cool the surface of the billet. The cold shell then hinders the contraction of

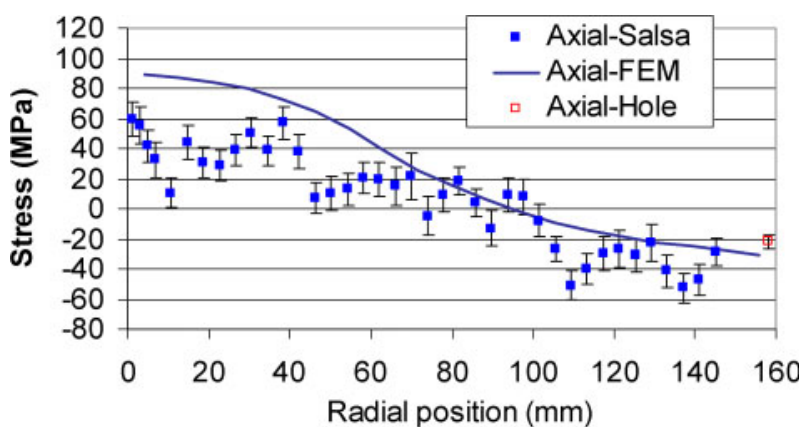

6 Comparison between computed and measured axial stress components within billet cast at $54 \mathrm{~mm} \mathrm{~min}{ }^{-1}$ 


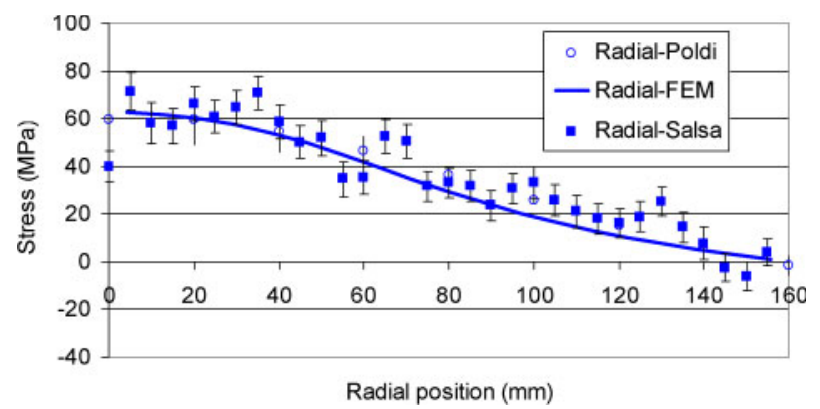

7 Comparison between computed (FEM) and measured radial stress components within billet cast at 66 $\mathrm{mm} \min ^{-1}$

the hot core region, leading to large interior tensile stresses. This effect is known as 'skin-core effect'. ${ }^{27}$ Furthermore, the agreement between the measured stress components and the FE predictions is very good for the radial and hoop components and weaker for the axial component, especially at the billet centre where FE results overestimate the stress level. The hole drilling method yields a hoop stress at $-84 \mathrm{MPa}$, which remains questionable.

The locations where the axial and hoop stress components change sign are also very close to the measured ones. Note also that the measured radial stress component at the billet surface is $0.65 \mathrm{MPa}$, whereas it should be zero. This gives us an idea of the precision that can be obtained with such neutron measurements.

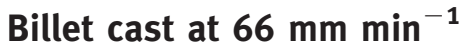

Residual strains on the $0.6 \mathrm{~m}$ long AA 6063 billet section cast at $66 \mathrm{~mm} \mathrm{~min}^{-1}$ were measured at the two neutron diffractometers, POLDI and SALSA. As the measuring time was reduced at SALSA owing to a higher neutron flux, roughly 32 residual strain measurements were made along the radius of the billet in $\sim 5 \mathrm{~mm}$ increments. Again, the mean stress free lattice parameter, 4.0504 $\AA$ was used as no substantial variation along the radius was found at SALSA and POLDI.

The radial distribution of the three stress components has been calculated at each radial position using equation (1). These stresses are shown in Figs. 7-9, along with the predicted stresses from the FE model and the hoop and axial values measured at the billet surface using the hole drilling method. The statistical error is larger for the axial stress at the billet centre owing to a

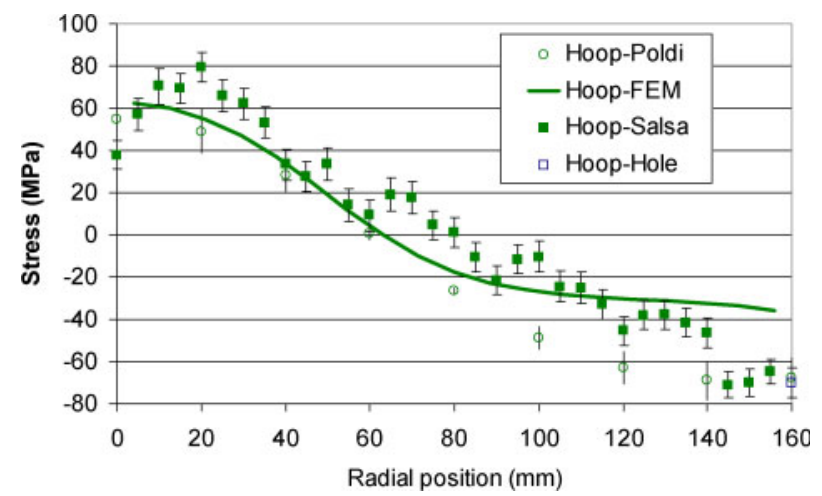

8 Comparison between computed (FEM) and measured hoop stress components within billet cast at 66 $\mathrm{mm} \min ^{-1}$

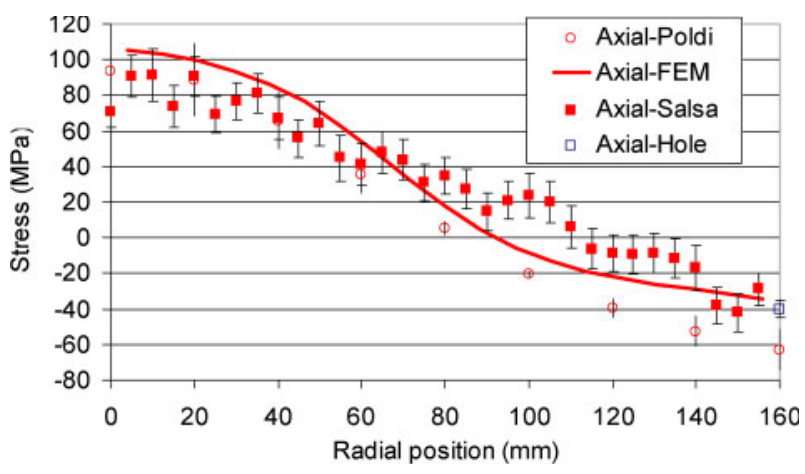

9 Comparison between computed (FEM) and measured axial stress components within billet cast at 66 $\mathrm{mm} \min ^{-1}$

longer beam path length, but still below $10 \mathrm{MPa}$. As for the billet cast at $54 \mathrm{~mm} \mathrm{~min}{ }^{-1}$, the centre of the billet is in triaxial tension, whereas its surface is in compression in the hoop and axial directions. Again, the agreement between the stress components measured at SALSA and POLDI and the FE predictions is very good for all three components. The FE results always fall within the measured values except near the billet surface for the hoop stress and at the billet centre for the axial stress. Again, the locations where the axial and hoop stress components change sign are also very close to the measured ones. Note also that the measured radial stress component close to the billet surface, in reality $4 \mathrm{~mm}$ under the surface, is $-1.65 \mathrm{MPa}$ at POLDI and $4 \mathrm{MPa}$ at SALSA and tend to zero when approaching the billet surface in spite of possible small texture and grain size effect at the very surface. Finally, the two values measured at the billet surface using the hole drilling method are within the other measured results (cf. Figs. 8 and 9).

A good indication of the validity of the neutron diffraction measurements is the value of radial and hoop stress components at the zero radial position. Indeed, at the billet centreline and for symmetry reasons, both radial and hoop stresses and strains are equal in materials with Poisson's ratio lower than $0 \cdot 5$. This is the case at $54 \mathrm{~mm} \mathrm{~min}^{-1}$ (cf. Figs. 4 and 5) and $66 \mathrm{~mm} \min ^{-1}$ (cf. Figs. 7 and 8), where measured axial and hoop stresses are identical at the billet centre.

The overall agreement between FE results and measured values induces confidence in the numerical model. As the casting speed increases, the stress level both in compression at the billet surface and in tension in the interior increases slightly. Nevertheless, the FE model underestimates the level of compression (hoop stress) at the billet surface. This can be attributed to a poor description of the cooling conditions along the billet surface during casting. In addition, kinematic hardening is not taken into account, although stresses change sign from tension to compression at the very billet surface during casting. ${ }^{1}$ In addition, the values measured using the hole drilling method can be questioned as the billet surface is not planar, as the stresses might change substantially over the $4 \mathrm{~mm}$ depth of the hole drilled under the billet surface and as the method is reported to be valid only if residual stresses are lower than the yield stress to avoid any localised yielding during drilling. ${ }^{25}$ 
Table 2 Linear and volumetric elastic energies as function of casting speed

\begin{tabular}{llll}
\hline & \multicolumn{3}{c}{$\begin{array}{l}\text { Elastic } \\
\text { energy } \\
\text { per unit }\end{array}$} \\
$\begin{array}{llll}\text { Casting speed } \\
V_{\text {cast }} / \mathrm{mm} \mathrm{min}^{-1}\end{array}$ & $\begin{array}{l}\text { per unit length } \\
W / H / \mathrm{kJ} \mathrm{m}^{-1}\end{array}$ & $\begin{array}{l}\text { volume } \\
D / \mathrm{kJ} \mathrm{m}^{-3}\end{array}$ & $\begin{array}{l}D / V_{\text {cast }} / \mathrm{kJ} \\
\mathrm{min} \mathrm{mm}^{-1} \mathrm{~m}^{-3}\end{array}$ \\
\hline 54 & 0.975 & 12.1 & 0.2241 \\
66 & 1.2 & 14.8 & 0.2242 \\
\hline
\end{tabular}

Finally, possible precipitation of stable or metastable phases might occur during the cooling of the solid metal and could explain the stress plateaus observed at low casting speed in Figs. 4-6. These plateaus disappear at high casting speed owing to higher cooling rates. Transmission electron microscopy and small angle X-ray scattering are to be carried out at different distances from the billet centreline in order to determine the nature and size of these precipitates.

\section{Stored elastic energy}

The stored elastic energy in a billet section of length $H$ and radius $R$ is given by

$$
W=\frac{1}{2} \int_{\mathrm{V}} \sigma: \varepsilon d V=2 \pi H \int_{0}^{\mathrm{R}} \frac{\sigma_{\mathrm{r}} \varepsilon_{\mathrm{r}}+\sigma_{\theta} \varepsilon_{\theta}+\sigma_{\mathrm{z}} \varepsilon_{\mathrm{Z}}}{2} r \mathrm{~d} r
$$

As the FE results fall within the measured values (cf. Figs. 5-7 for the low casting speed and Figs. 8-10 for the high casting speed), the stored energy can be calculated using the FE predictions. Calculating integral (3) for our two billet samples $(R=160 \mathrm{~mm})$ yields an elastic energy of $W / H$ per unit length and a density of elastic energy per unit volume $D=W /\left(\pi R^{2} H\right)$. The results are summarised in Table 2. Stored elastic energies are larger than the values reported after quenching, from $0 \cdot 5$ to $7.5 \mathrm{~kJ} \mathrm{~m}^{-3}$ for $2 \mathrm{xxx}$ and $7 \mathrm{xxx}$ aluminium thick plates. ${ }^{28}$ Indeed, thermally induced deformations and associated stress build-up are of the same nature in casting and in quenching, although temperatures are higher in casting compared to quenching, and heat extraction rates might differ substantially. As the casting speed increases, the stored elastic energy per unit length or volume increases. The higher this value, the higher is the risk to get erratic dissipation of energy during casting (solidification or cold cracking) or when sawing the as cast billet. ${ }^{19}$ Casting recipes should be adapted in order to keep this value at an acceptable level.

It is interesting to notice that the ratio of the stored elastic energy to the casting speed is constant. In other words, the stored energy density is proportional to the casting speed at least within the range of speeds investigated here. This is explained by the fact that during casting, the liquid pool that forms within the billet is also proportional to the casting speed. The deeper the liquid pool is, the greater are the thermally induced deformations and associated stresses.

\section{Conclusions}

The as cast residual stresses have been measured on steady state sections of an AA 6063 extrusion billet cast at two different casting speeds in order to generate different residual stress profiles. Neutron diffraction measurements have been carried out at SALSA,
ILL-Grenoble, France, and POLDI, PSI-Villigen, Switzerland. In addition, stresses at the billet surface have been measured using the hole drilling strain gage method. All the measured results agree relatively well with the computed values of a FE model of DC casting considering the numerous input parameters entering into the model (alloy properties, cooling conditions, etc.). In particular, the locations where the axial and hoop stresses change sign are well predicted by the model. Still, the FE model underestimates the level of compression (hoop stress) at the billet surface. This can be attributed to a poor description of the cooling conditions along the billet surface during casting and to the absence of kinematic hardening in the mechanical description. Finally, it is shown that the stored elastic energy within the as cast billet varies linearly with the casting speed, at least within the range of investigated speeds that correspond to production conditions. Further analysis of possible phase precipitation taking place during casting is still under progress.

\section{Acknowledgements}

The authors express their deep acknowledgements to Constellium for providing the two billet sections on which neutron diffraction measurements and hole drilling have been carried out and to the Swiss Spallation Neutron Source at PSI and to the international Neutron Source at ILL for the provision of beam time.

\section{References}

1. J.-M. Drezet: 'Direct chill and electromagnetic casting of aluminium alloys: thermomechanical effects and solidification aspects', PhD thesis, EPF-Lausanne, Lausanne, Switzerland, 1996.

2. J.-M. Drezet and M. Rappaz: 'Modelling of ingot distortions during direct chill casting of aluminium alloys', Metall. Mater. Trans. A, 1996, 27A, 3214-3225.

3. B. Hannart, F. Cialti and R. V. Schalkwijk: 'Thermal stresses in DC casting of aluminum slabs: application of a finite element model', in 'Light metals 1994', (ed. A. T. Tabereaux), 879-887; 1994, Warrendale, PA, TMS.

4. H. Fjaer and A. Mo: 'Alspen: a mathematical model for thermal stresses in direct chill casting of aluminium billets', Metall. Mater. Trans. B, 1990, 21B, 1049-1061.

5. J. Sengupta, S. L. Cockcroft, D. M. Maijer and A. Larouche: 'Quantification of temperature, stress, and strain fields during the start up phase of DC casting process by using a 3D fully coupled thermal and stress model for AA5182 ingots', Mater. Sci. Eng. A, 2005, A397, 157-177.

6. W. Boender, A. Burghardht, E. P. van Klaveren and J. Rabenberg: 'Numerical simulation of DC casting, interpreting the results of a thermo-mechanical model', in 'Light Metals 2004', (ed. A. T. Tabereaux), 679-684; 2004, Warrendale, PA, TMS.

7. O. Ludwig, J.-M. Drezet, B. Commet and B. Heinrich: 'Modelling of internal stresses in DC casting and sawing of high strength aluminum alloys slabs', in 'Modeling of casting welding and advanced solidification processes', (ed. C.-A. Gandin and M. Bellet), 185-192; 2006, Nice, TMS

8. W. Droste, J.-M. Drezet, G.-U. Gruen and W. Schneider: '3D modeling of ingot geometry development of DC-cast aluminium ingots during the start-up phase, in continuous casting',(ed. K. Ehrke and W. Schneider), 175-183; 2000, Frankfurt, DGM/Wiley$\mathrm{VCH}$.

9. W. Droste, G.-U. Grün, W. Schneider and J.-M. Drezet: 'Thermomechanical modeling to predict shrinkage, shape and mold openings for dc-cast rolling ingots', in 'Light metals', (ed. W. Schneider), 703-708; 2002, Seattle, WA, TMS.

10. A. B. Phillion, D. Maijer and S. L. Cockcroft: 'Coupled thermalstress model of the start-up phase of the aluminum direct chill casting process: predictions relating to hot tearing', Proc. Conf. on 'Modeling of casting, welding and advanced solidification processes XI', Opio, France, May 2006, TMS, 807-814. 
11. J. W. Evans: 'The use of electromagnetic casting for $\mathrm{Al}$ alloys and other metals', JOM, 1995, 47, 38-41.

12. K. Escobar, B. Gonzalez, J. L. Ortiz, P. N. Nguyen, D. Bowden, J. Foyos, J. Ogren, E. W. Lee and O. S. Es-Said: 'On the residua stress control in aluminium alloys 7050', Mater. Sci. Forum, 2002, 396-402, 1235-1240.

13. S. Ganguly, M. E. Fitzpatrick and L. Edwards: 'Comparative neutron and synchrotron X-rax diffraction studies to determine residuals stress on an as-welded AA2024 plate', Mater. Sci. Forum, 2005, 790-491, 223-228.

14. J. Moriceau: 'Thermal stresses in continuous DC casting of $\mathrm{Al}$ alloys, discussion of hot tearing mechanisms', in 'Light metals', (ed R. Rentsch), 119-133; 1975, Warrendale, PA, TMS.

15. S. A. Levy.et al: 'Residual stress measurements for studying ingot cracking', in 'Light metals', (ed. H. Forberg); 1974, 571-585, Warrendale, PA, TMS

16. J. Lu: in 'Handbook of measurement of residual stresses', (ed. J. Lu); 1996, Lilburn, GA, Society for Experimental Mechanics, Inc./The Fairmont Press.

17. H. Hao, D. M. Maijer, M. A. Wells, S. L. Cockcroft and R. B. Rogge: 'Prediction and measurement of residual stresses/strains in a direct chill casting magnesium alloy billet', Proc. Conf. on 'Magnesium technology', (ed. N. Neelameggham et al.), 223-228; 2005, Warrendale, PA, TMS.

18. J.-M. Drezet and A. Phillion: 'As-cast residual stresses in an aluminum alloy AA6063 billet: neutron diffraction measurements and finite element modeling', Metall. Mater. Trans. A, 2010, 41A, 3396-3404.

19. J.-M. Drezet, O. Ludwig, C. Jaquerod and E. Waz: 'Fracture prediction during sawing of DC cast high strength aluminium alloy rolling slabs', Int. J. Cast Met. Res., 2007, 20, (3), 163-170.
20. 'Pulse overlap time-of-flight diffractomer, POLDI', Paul Scherrer Institut, Villigen, Switzerland, http://poldi.web.psi.ch/

21. 'Strain imager for engineering applications SALSA', Institut Laue Langevin, Grenoble, France, http://www.ill.eu/instruments-support/ instruments-groups/instruments/salsa/

22. C. Sigli, L. Maenner, C. Sztur and R. Shahani: 'Phase diagram, solidification and heat treatment of aluminium alloys', Proc. 6th Int. Conf. on 'Aluminum Alloys', ed. T. Sato et al., Toyohashi, Japan, July 1998, Japan Institute of Light Metals, p. 87-98.

23. G. A. Webster: 'VAMAS TWA 20 standard', ISO technical report, ISO, Geneva, Stwizerland, 2001.

24. J.-M. Drezet, A. Evans, C. Jaquerod and A. Phillion: 'Measurement of as-cast residual stresses in an aluminium alloy AA6063 billet using neutron diffraction', Proc. Jim Evans Honorary Symp., (ed. B. Li et al.), 43-52; 2010, Warrendale, PA, TMS.

25. 'Measurement of residual stresses by the hole-drilling strain gage method', Tech note no. TN-503, Vishay Precision Group, http:// www.micro-measurements.com

26. 'Standard test method for determining residual stresses by the holedrilling strain-gage method', ASTM Standard E837, ASTM International, West Conshohocken, PA, USA, 1995.

27. J.-M. Drezet and M. Rappaz: 'Ingot distortions and residual stresses in direct chill casting of aluminium alloys', Proc. 4th Eur. Conf. on 'Residual stresses', (ed. S. Denis et al.), 357-366, 1996; Cluny, France.

28. F. Heymès, B. Commet, B. Dubost, P. Lassince, P. Lequeu and G. M. Raynaud: 'Development of new Al Alloys for distortion free machined aluminum aircraft components', Proc. 1st Int. Nonferrous Processing and Technology Conf., St Louis, MO, USA, March 1997, ASM International. 